\title{
Outcomes of direct acting antiviral therapy for treatment of HCV infection in patients with decompensated liver cirrhosis
}

\author{
Doaa Bakr ${ }^{1}$, Ibrahim Hassan ${ }^{1}$, Elsayed Abd-Elmaksood ${ }^{1, *}$, Ashraf Omar ${ }^{1}$, Mahmoud Awad $^{1}$ \\ ${ }^{1}$ Internal Medicine Department, Faculty of Medicine, Mansoura University, Egypt.
}

\begin{abstract}
Background and Aim: Direct acting antiviral agents (DAAs) are highly effective and safe treatment in patients with chronic hepatitis $\mathrm{C}$ infection (CHC). The aim of this study is to evaluate outcomes of direct acting antiviral drugs for treatment of $\mathrm{HCV}$ infection in patients with decompensated liver cirrhosis.

Materials and methods: This study included $115 \mathrm{HCV}$ decompensated cirrhotic patients who were treated according to the Egyptian National Treatment Program for Hepatitis C Virus. The patients were divided into 3 groups; Group I, included 70 patients received sofosbuvir and daclatasvir for 24 weeks, Group II, included 18 patients received sofosbuvir, daclatasvir and ribavirin for 12 weeks and control group, included 27 patients refused antiviral therapy. Results: The sustained virologic response (SVR) in the present study was $91 \%(89.3 \%$ in group I and $92.3 \%$ in group II) with non-significant difference between both groups. Compared to untreated control group and to baseline parameters, both treated groups showed significant improvement as regarding, liver function, INR, creatinine, Child-Turcott-Pugh score and MELD score12 weeks post-treatment. There was a statistically significant decrease in variceal bleeding, ascites and hepatic encephalopathy in treated group compared to control group with no statistically significant difference recorded between the three studied groups regarding hepatocellular carcinoma, hepatorenal syndrome, spontaneous bacterial peritonitis and pleural effusion. Conclusions: Treatment of decompensated HCV cirrhotic patients with DAAs had SVR about $91 \%$. SVR is associated with improvement in liver function and a significant reduction cirrhotic related complications.
\end{abstract}

\section{Introduction}

Chronic hepatitis $\mathrm{C}$ virus (HCV) infection is a major health burden in Egypt and worldwide 1. HCV causes chronic hepatitis in $60 \%-80 \%$ of the patients, and $10 \%-$ $20 \%$ of those patients will develop cirrhosis over 20-30 years following infection. About $1 \%-5 \%$ of the patients with liver cirrhosis may develop liver cancer and 3\%-6\% may decompensate during the following 20-30 years. The risk of death in the following year after an episode of decompensation is between $15 \%$ and $20 \%{ }^{2}$.

Keywords: Hepatitis C virus; direct-acting antiviral agents; sustained virologic response; ascites, alpha fetoprotein Received: 2-12-2021 ; Accepted: 21-12-2021

* Corresponding author. Email: maksood1963@yahoo.com
Viral eradication in patients with chronic $\mathrm{HCV}$ infection has been shown to result in improvements in medium- and long-term outcomes assessed both by patient reported quality of life measurements and mortality/morbidity ${ }^{3}$. Newly, direct-acting antiviral (DAAs) that target specific HCV viral proteins have been settled for the treatment of chronic hepatitis $\mathrm{C}$ virus infection with an brilliant safety profile and encouraging clinical outcomes. These molecules include a range of non-structural (NS) NS3/4A protease, NS5B polymerase and NS5A inhibitors ${ }^{4-6}$.

In general, patients with decompensated cirrhosis (Child-Pugh B/C) have lower response rates than patients with compensated cirrhosis (Child-Pugh A). Reduced rates of SVR in decompensated cirrhosis were explained by the extensive porto-systemic collaterals and advanced fibrotic parenchyma which provides dormant foci for viral reactivation. However, safety issues regarding the use of DAAs among those patients with the most advanced liver disease have arisen ${ }^{7}$.

Multiple long-term follow-up studies have shown that patients with compensated cirrhosis who achieve sustained virological response (SVR) with interferon (IFN)-based therapy have improved long-term outcomes ${ }^{8}$. With direct acting antivirals (DAAs), however, even patients with compensated cirrhosis achieve SVR rates over $95 \%$ 9,10. Moreover, it was found that treatment was safe and effective inwith decompensated cirrhosis ${ }^{11}$. The aim of this study is to evaluate outcomes of direct acting antiviral drugs for treatment of $\mathrm{HCV}$ infection in patients with decompensated liver cirrhosis.

\section{Materials and methods}

This prospective study included 115 HCV decompensated cirrhotic patients accepted treatment by direct acting antiviral drugs (DAAs) according to the National committee for control of Viral Hepatitis (NCCVH) protocol in Internal Medicine Department, Mansoura university Hospital under the supervision of Ministry of Health from July 2017 to September 2019. The study was ethically approved by the Medical Research Ethics Committee, Faculty of Medicine, Mansoura University. A written informed consent was obtained from all patients after revealing the objective of the research, its advantages and hazards and duration of the research. The patients were divided into 3 groups; Group I; included 70 patients received sofosbuvir (SOF) and daclatasvir (DAC) for 24 weeks, Group II; included 18 patients received sofosbuvir, daclatasvir and ribavirin for 12 weeks and 
control group, included 27 patients refused antiviral therapy.

Inclusion criteria: Chronic HCV patients (diagnosed by positive PCR) with decompensated cirrhotic and eligible for treatment with direct acting antiviral therapy according to $(\mathrm{NCCVH})$ treatment protocol. The diagnosis of cirrhosis based on, history taking, clinical and radiological examination, and laboratory tests. Liver decompensation depended on the presence of one or more of the following ascites, jaundice, past history of hepatic encephalopathy, past history of variceal bleeding.

Exclusion Criteria: included, any other causes of liver cirrhosis e.g chronic HBV infection, previous liver transplantation and previously ablated $\mathrm{HCC}$ or active $\mathrm{HCC}$, patients co-infected with HIV or HBV, other organ failure (heart failure \&renal failure).

Methods: All patients subjected to the following, detailed history taking, full clinical and radiological examination (Ultrasound of liver and triphasic CT when indicated), ECG (ECHO in patient > $65 \mathrm{y}$ or cardiac patient), upper GI endoscopy before starting treatment and every 3 months as regular surveillance for diagnosis and management of esophageal and gastric varices.

Laboratory investigation: Included, liver function tests (albumin, bilirubin, alanine transaminase, aspartate transaminase) prothrombin time/ international normalized ratio (INR), fasting blood sugar, serum creatinine, complete blood count, HBs antigen, HCV antibodies by ELISA, polymerase chain reaction for $\mathrm{HCV}$, anti-nuclear antibodies, and alpha-fetoprotein. Child Pugh score and MELD score calculation.

Follow up. To assess efficacy, safety and outcomes of drugs, all patients were followed up every 4 weeks during treatment, at the end of treatment and 12 weeks after treatment.

Endpoints of the study.

Primary end point: Follow up of the patients up to 12 weeks after end of treatment.

Secondary end point: Any serious adverse events that lead to discontinuation of treatment and /or death.

\section{Statistical analysis}

Data were entered and analyzed using IBM-SPSS software (IBM Corp. Released 2017. IBM SPSS Statistics for Windows, Version 25.0. Armonk, NY: IBM Corp.). Qualitative data were expressed as frequency and percentage. Quantitative data were initially tested for normality using Kolmogorov-Smirnov and Shapiro-Wilk's test with data being normally distributed if $\mathrm{p}>0.050$. Presence of significant outliers (extreme values) was tested for by examining box plots. Quantitative data were expressed as mean \pm standard deviation (SD) if normally distributed or median and interquartile range (IQR) if not. Chi-Square test with Bonferroni method to adjust $\mathrm{p}$ values when comparing column proportions was used. Monte Carlo significance was used when appropriate.Quantitative data for three or more groups. One-Way ANOVA test was used for normally distributed data in all groups with no significant outliers, otherwise the non-parametric alternative Kruskal-Wallis $\mathrm{H}$ test was used. Repeatedmeasures ANOVA test was used for normally distributed data in all measurements with no significant outliers, otherwise the non-parametric alternative Friedman's test was used. For any of the used tests, results were considered as statistically significant if $\mathrm{p}$ value $\leq 0.050$.

Results

This prospective study included 115 HCV decompensated cirrhotic patients. 14 patients were excluded from group I (10 patients missed follow-up during treatment course and 4 patient after end of therapy. 5 patients were excluded from group II (3 patients missed follow-up during treatment course and 2 patient after end of therapy).

There is no statistically significant difference between 3 studied groups regarding, age $(56.7 \pm 6.1,57.28 \pm 6.96$ and $59.96 \pm 5.1$ respectively; $\mathrm{p}=0.339)$, gender $(\mathrm{p}=$ $0.364)$, DM $(47.1 \%, 33.3 \%$ and $55.6 \%$ respectively; $\mathrm{p}=$ $0.342)$ and hypertension $(51.4 \%, 66.7 \%$ and $66.7 \%$ respectively; $\mathrm{p}=0.272$ ). Moreover, no statistically significant difference as regarding sustained virologic response in group I compared to group II $(89.3 \%$ versus $92.3 \%, p=0.129)$.

Table (1) shows the baseline data of the studied groups. There was statistically significant increase in number of patients presented by ascites in group I compared to both group II and control group. Also statistically significant increase in number of patients presented by ascites in control group compared to group II. As regarding hepatic encephalopathy (HE) there was no statistically significant difference when comparing group I to group II, however, statistically significant increase was found in control group versus both group 1 and group II. Regarding number of patients presented by history of variceal bleeding, there is no statistically significant difference when comparing the three studied groups. There is statistically significant increase in hemoglobin level in group II compared to both group I and control group with no significant statistical difference when comparing group I to control group. No significant statistical difference was found as regard platelets count when compared group I to both group II and control group, however, there was a statistically significant increase in platelets count in group II versus control group.

There is statistically significant decrease in serum total bilirubin level in group II compared to both group I and control group with no significant statistical difference when compared group I to control group. There is statistically significant increase in serum creatinine and AFP level in control group compared to group I and group II with no significant statistical difference when comparing group I to group II. As regarding AST, ALT, serum albumin and INR levels at baseline there is no statistically significant difference when compared the three studied groups. Table (2) shows the clinical and laboratory characteristics at baseline and 12 weeks post-treatment among the studied groups. As regarding ascites there was 
significant decrease in the degree of ascites in group I and group II - 12 weeks after treatment compared to baseline, while control group showed insignificant change in the degree of ascites during the same period of follow up.

As regarding hepatic encephalopathy and variceal bleeding, there is a statistically significant decrease in number of cases during follow up - 12 weeks posttreatment compared to baseline in group I, while in group II and control group there are no statistically significant change. There was a significant increase in HB level and platelet count in group I. A significant increase in HB level at 12 week post-treatment compared to baseline with no significant change in platelets count was found in group II, however control group showed insignificant change in both $\mathrm{HB}$ and platelet count.

There was a statistically significant decrease in ALT, AST and total bilirubin levels in group I and group II - 12 weeks post-treatment compared to baseline, while no statistically significant difference observed in control group.. As regarding serum albumin, there is a statistically significant increase in group I and group II at 12 week post-treatment compared to baseline, while, in control group there is a statistically significant decrease in serum albumin at similar time compared to baseline.

There is a statistically significant decrease in INR and serum creatinine in both group I and group II - at 12 weeks post-treatment compared to baseline, while no statistically significant difference observed in control group at similar time. No statistically significant change observed in both group I and group II regarding AFP however, in control group there was a statistically significant increase during the similar time of follow up.

Table (3) shows a statistically significant decrease of mean Child-Turcott-Pugh (CTP) score in both group I and group II - 12 weeks post-treatment compared to baseline, while CTP score in control group showed a statistically significant increase during the similar follow period compared to baseline. Table (4) shows a statistically significant decrease in MELD score in both group I and group II at 12 weeks post-treatment compared to baseline but in control group there was a statistically significant increase in MELD score at the similar period compared to baseline. Table (5) shows a statistically significant decrease in ascites, variceal bleeding and hepatic encephalopathy in both group I and group II compared to control group with no statistically significant difference recorded between the three studied groups regarding other complications ( HCC, HRS, SBP, pleural effusion and jaundice).

\section{Discussion}

In our study, the overall sustained virologic response (SVR) was $91 \%$ in patients with decompensated liver cirrhosis. The sustained virologic response was $89.3 \%$ in group I received sofosbuvir and daclatasvir for 24 weeks, and $92.3 \%$ in group II patients received sofosbuvir, daclatasvir and ribavirin for 12 weeks with non-significant difference between both treated groups. The American Association for the Study of Liver Diseases and the European Association for the Study of the Liver (EASL) guidelines recommend that, in patients with decompensated cirrhosis, all-oral DAAs regimens comprising sofosbuvir, ledipasvir, daclatasvir and RBV can be used ${ }^{12,13}$. These recommended all-oral combination regimens are generally associated with SVR rates similar or slightly lower to that of patients without decompensated cirrhosis. In previous studies, the SVR in decompensated liver cirrhosis was variable. The SVR rate was $81 \%$ among these patients in study by Krassenburg et al ${ }^{14}$, however, many Egyptian studies found a high SVR. Omar et al ${ }^{15}$, reported that chronic $\mathrm{HCV}$ decompensated patients who were treated for 12 weeks with $(\mathrm{SOF}+\mathrm{DAC} \pm \mathrm{RBV})$ showed overall, $95.1 \%$ SVR12 $(95.4 \%$ among patients treated without ribavirin and $94.7 \%$ for patients treated with ribavirin) and Wahsh et al ${ }^{16}$ found that, treated chronic HCV cirrhotic decompensated patients with the same regimen and period obtained SVR12 in $88.89 \%$. Hanafy et al treated $160 \mathrm{HCV}$ patients with decompensated cirrhosis who received SOF/DAC $\pm \mathrm{RBV}$ for 3 months and SVR was achieved in 144 patients $(90 \%){ }^{17}$. Welzel et al, assessed the effectiveness and safety of $(\mathrm{SOF}+\mathrm{DAC} \pm \mathrm{RBV})$ in treating patients with advanced liver disease with different HCV genotypes and found that, SVR12 was achieved by $91 \%$ of patients ${ }^{18}$. Our study declared that, DAAtherapy in decompensated cirrhosis patients producing improvement in liver function denoting marked improvement of cellular injury after treatment of chronic HCV infection by DAAs. In accordance with this result, many studies found improvement in in liver function after achieving DAAs-SVR in decompensated liver cirrhosis. Verna et al demonstrated that, decompensated HCVrelated cirrhosis treated with DAAs, had improvements in MELD, total bilirubin, or albumin at long-term follow-up (after achieving SVR12) ${ }^{19}$. Another study by Hanafy et al, reported a significant improvement in the baseline laboratory parameters in treated patients with or without ribavirin. They reported significant improvement in serum albumin from 2.5 to $2.9 \mathrm{gm} / \mathrm{dl}$; and decreasing bilirubin from 1.7 to $1.4 \mathrm{mg} / \mathrm{dl}$ however, INR showed insignificant reduction. In contrast control group showed significant deterioration of bilirubin and INR and insignificant decrease in mean albumin17. In addition, Welzel et al assessed the effectiveness and safety of SOF/DAC \pm RBV in patients with advanced liver disease and showed that total bilirubin decreased by a median $0.2 \mathrm{mg} / \mathrm{d}$, alanine aminotransferase (ALT) decreased by 37 IU/L, albumin increased by $2.0 \mathrm{~g} / \mathrm{L}$ and platelets increased by $7.0 \times 109$ cells/L by comparing baseline measurements to 12 week post-treatment measurements. MELD score improved or remained unchanged in $47 \%$ of treated patients, respectively; improvements in liver functions were observed in $58 \%$ of patients with decompensated cirrhosis $^{18}$ Our study showed a statistically significant decrease of mean CTP score and MELD score in both group I and group II during follow at 12 weeks posttreatment compared to baseline while, CTP score in control group showed a statistically significant increase during follow up compared to baseline. 
Table 1. Baseline clinical and laboratory data among the studied groups.

\begin{tabular}{|c|c|c|c|c|}
\hline Variable & $\begin{array}{c}\text { Group I } \\
\mathbf{N}=70\end{array}$ & $\begin{array}{c}\text { Group II } \\
\mathrm{N}=18\end{array}$ & Control $\mathrm{N}=27$ & $P$ value \\
\hline Ascites: N/\% & $56(80 \%)$ & $3(16.7 \%)$ & $6(22.2 \%)$ & $\begin{array}{l}\mathrm{p} 1<0.001 \\
\mathrm{p} 2=0.001 \\
\mathrm{p} 3=0.001\end{array}$ \\
\hline $\begin{array}{l}\text { Hepatic } \\
\text { Encephalopathy: N/\% }\end{array}$ & $6(8.6 \%)$ & $2(11.1 \%)$ & $9(33.3 \%)$ & $\begin{array}{l}\mathrm{p} 1=0.738 \\
\mathrm{p} 2=0.008 \\
\mathrm{p} 3=0.008\end{array}$ \\
\hline Variceal bleeding: N/\% & $6(8.6 \%)$ & $3(16.7 \%)$ & $3(11.1 \%)$ & $\begin{array}{l}\mathrm{p} 1=0.312 \\
\mathrm{p} 2=0.60 \\
\mathrm{p} 3=0.60\end{array}$ \\
\hline Hemoglobin $(\mathrm{gm} / \mathrm{dl})$ & $(11.48 \pm 1.32)$ & $(12.27 \pm 1.29)$ & $(11.03 \pm 0.93)$ & $\begin{array}{l}\mathrm{p} 1=0.018 \\
\mathrm{p} 2=0.111 \\
\mathrm{p} 3=0.001\end{array}$ \\
\hline Platelet count $\left(/ \mathrm{ccm}^{3}\right)$ & $77.0(62.25-105.0)^{\mathrm{b}}$ & $87.0(51.0140 .0)^{\mathrm{a}}$ & $80.0(64.097 .0)^{\mathrm{a}}$ & $\begin{array}{l}\mathrm{p} 1=0.250 \\
\mathrm{p} 2=0.451 \\
\mathrm{p} 3=0.001\end{array}$ \\
\hline ALT (IU/L) & $38.0(28.75-50.25)$ & $42.0(26-56)$ & $37(37-39)$ & $\begin{array}{l}\mathrm{p} 1=0.669 \\
\mathrm{p} 2=0.845 \\
\mathrm{p} 3=0.822\end{array}$ \\
\hline AST (IU/L) & $41.5(35-56.25)$ & $49.0(37.0-73.0)$ & $46.0(42.0-65.0)$ & $\begin{array}{l}\mathrm{p} 1=0.082 \\
\mathrm{p} 2=0.367 \\
\mathrm{p} 3=0.396\end{array}$ \\
\hline Serum bilirubin (mg/dl) & $(2.78 \pm 0.66)$ & $(2.56 \pm 0.58)$ & $(2.73 \pm 0.53)$ & $\begin{array}{l}\mathrm{p} 1=0.001 \\
\mathrm{p} 2=0.720 \\
\mathrm{p} 3=0.001\end{array}$ \\
\hline Serum albumin $(\mathrm{gm} / \mathrm{dl})$ & $2.98 \pm 0.34$ & $3.08 \pm 0.30$ & $3.07 \pm 0.2$ & $\begin{array}{l}\mathrm{p} 1=0.209 \\
\mathrm{p} 2=0.222 \\
\mathrm{p} 3=0.855\end{array}$ \\
\hline INR & $1.54 \pm 0.26$ & $1.464 \pm 0.122$ & $1.590 \pm 0.176$ & $\begin{array}{l}\mathrm{p} 1=0.216 \\
\mathrm{p} 2=0.309 \\
\mathrm{p} 3=0.068\end{array}$ \\
\hline $\operatorname{AFP}(\mathrm{ng} / \mathrm{ml})$ & $11.5(7.88-18.0)$ & $9.80(7.30-11.0)$ & $12.3(7.30-89.6)$ & $\begin{array}{l}\mathrm{p} 1=0.828 \\
\mathrm{p} 2=0.001 \\
\mathrm{p} 3=0.001\end{array}$ \\
\hline Creatinine (mg/dl) & $(0.947 \pm 0.349)$ & $(0.822 \pm 0.175)$ & $(1.237 \pm 0.26)$ & $\begin{array}{l}\mathrm{p} 1=0.129 \\
\mathrm{p} 2=0.001 \\
\mathrm{p} 3=0.001\end{array}$ \\
\hline
\end{tabular}

pI = group I versus group II; p2= group I versus control group; $p 3=$ group II versus control group.

Table 2. Biochemical characteristics at baseline and 12 weeks post-treatment among the studied groups.

\begin{tabular}{|c|c|c|c|c|}
\hline Parameter & Time & $\begin{array}{c}\text { At baseline } \\
(G \mathrm{I}, \mathbf{N}=\mathbf{7 0}) \\
(\mathrm{G} \text { II, } \mathbf{N}=\mathbf{1 8}) \\
(\mathrm{CG}, \mathbf{N}=\mathbf{2 7})\end{array}$ & $\begin{array}{c}12 \text { week-post-treatment } \\
(\mathrm{G} \mathrm{I}, \mathrm{N}=56) \\
(\mathrm{G} \text { II, } \mathrm{N}=13) \\
(\mathrm{CG}, \mathrm{N}=18)\end{array}$ & P-value \\
\hline \multirow{3}{*}{$\begin{array}{l}\text { Hemoglobin } \\
(\mathrm{gm} / \mathrm{dl})\end{array}$} & Group I & $11.48 \pm 1.32$ & $11.90 \pm 1.21$ & 0.001 \\
\hline & Group II & $12.27 \pm 1.29$ & $12.41 \pm 1.54$ & 0.001 \\
\hline & Control group & $11.03 \pm 0.93$ & $10.86 \pm 0.87$ & 0.086 \\
\hline \multirow[t]{2}{*}{ Platelets $\left(10^{9} / /\right)$} & Group I & $77.0(62.25-105.0)$ & $78.0(66.5-109.25)$ & $<0.001$ \\
\hline & Group II & $87.0(51.0-140.0)$ & $81.5(74.0-130.0)$ & 0.223 \\
\hline
\end{tabular}




\begin{tabular}{|c|c|c|c|c|}
\hline & Control group & $80.0(64.0-97.0)$ & $83.0(76.0-89.0)$ & 0.135 \\
\hline \multirow[t]{3}{*}{ ALT (IU/I) } & Group I & $38.0(28.75-50.25)$ & $33.0(27.0-38.0)$ & $<0.001$ \\
\hline & Group II & $42.0(26-56)$ & $31.0(28.0-37.0)$ & $<0.001$ \\
\hline & Control group & $37(37-39)$ & $35.0(29.0-48.0)$ & 0.23 \\
\hline \multirow[t]{3}{*}{ AST (IU/I) } & Group I & $41.5(35-56.25)$ & $38.5(35-46)$ & $<0.001$ \\
\hline & Group II & $49.0(37.0-73.0)$ & $37(32-57)$ & $<0.001$ \\
\hline & Control group & $46.0(42.0-65.0)$ & $51(40-57)$ & 0.922 \\
\hline \multirow{3}{*}{$\begin{array}{l}\text { Serum bilirubin } \\
(\mathrm{mg} / \mathrm{dl})\end{array}$} & Group I & $2.784 \pm 0.66$ & $2.14 \pm 0.567$ & 0.006 \\
\hline & Group II & $2.56 \pm 0.58$ & $2.17 \pm 0.44$ & 0.01 \\
\hline & Control group & $2.73 \pm 0.53$ & $2.819 \pm 0.64$ & 0.237 \\
\hline \multirow{3}{*}{$\begin{array}{l}\text { Serum albumin } \\
(\mathrm{gm} / \mathrm{dl})\end{array}$} & Group I & $2.98 \pm 0.34$ & $3.1 \pm 0.36 b$ & 0.001 \\
\hline & Group II & $3.08 \pm 030 \mathrm{a}$ & $3.45 \pm 0.32$ & 0.01 \\
\hline & Control group & $3.07 \pm 0.2$ & $2.84 \pm 0.162$ & 0.001 \\
\hline \multirow[t]{3}{*}{ INR } & Group I & $1.54 \pm 0.26$ & $1.42 \pm 0.213$ & 0.001 \\
\hline & Group II & $1.46 \pm 0.122$ & $1.372 \pm 0.13$ & 0.005 \\
\hline & Control group & $1.590 \pm 0.176$ & $1.602 \pm 0.162$ & 0.924 \\
\hline \multirow{3}{*}{$\begin{array}{l}\text { Alfa fetoprotein } \\
(\mathbf{n g} / \mathbf{m l})\end{array}$} & Group I & $11.5(7.88-18.0)$ & $10.5(5.35-15.5)$ & 0.06 \\
\hline & Group II & $9.80(7.30-11.0)$ & $8.9(7.2-11.7)$ & 0.223 \\
\hline & Control group & $12.3(7.30-89.6) \mathrm{a}$ & 13.6(7.3-93.0)ab & 0.049 \\
\hline \multirow{3}{*}{$\begin{array}{l}\text { Serum creatinine } \\
(\mathbf{m g} / \mathbf{d l})\end{array}$} & Group I & $0.947 \pm 0.349 \mathrm{ab}$ & $0.868 \pm 0.246 b$ & 0.006 \\
\hline & Group II & $0.822 \pm 0.175$ & $0.605 \pm 0.11$ & $<0.001$ \\
\hline & Control group & $1.237 \pm 0.26$ & $1.27 \pm 0.23$ & 0.201 \\
\hline
\end{tabular}

\section{CG, control group.}

Table 3: CTP score at baseline, and 12 week post-treatment among the studied groups.

\begin{tabular}{|c|c|c|c|c|c|c|c|c|}
\hline \multirow[t]{3}{*}{ Group } & \multicolumn{2}{|c|}{ CTP score } & \multicolumn{6}{|c|}{ CTP class } \\
\hline & \multirow[t]{2}{*}{ Baseline } & \multirow{2}{*}{$\begin{array}{l}12 \text { weeks- } \\
\text { Post- } \\
\text { treatment }\end{array}$} & \multicolumn{3}{|c|}{ Baseline } & \multicolumn{3}{|c|}{$\begin{array}{c}12 \text { weeks-Post-Post- } \\
\text { treatment }\end{array}$} \\
\hline & & & A & B & $\mathrm{C}$ & A & B & $\mathrm{C}$ \\
\hline Group I & $8.1 \pm 1.14^{\mathrm{ab}}$ & $7.56 \pm 1.27^{b}$ & 0 & $\begin{array}{c}57 \\
(81.4)\end{array}$ & $\begin{array}{c}13 \\
(18.6)\end{array}$ & $\begin{array}{c}15 \\
(26.8)\end{array}$ & $\begin{array}{c}38 \\
(67.9)\end{array}$ & $\begin{array}{c}3 \\
(5.3)\end{array}$ \\
\hline P value & \multicolumn{2}{|c|}{$\mathrm{P}<0.001$} & \multicolumn{6}{|c|}{$<0.001$} \\
\hline Group II & $7.50 \pm 0.51^{\mathrm{ab}}$ & $6.11 \pm 1.02^{b}$ & 0 & $\begin{array}{c}18 \\
(100.0)\end{array}$ & 0 & $\begin{array}{c}9 \\
(69.2)\end{array}$ & $\begin{array}{c}4 \\
(30.8)\end{array}$ & 0 \\
\hline$P$ value & \multicolumn{2}{|c|}{$\mathrm{P}<0.001$} & \multicolumn{6}{|c|}{0.001} \\
\hline $\begin{array}{l}\text { Control } \\
\text { Group }\end{array}$ & $8.22 \pm 1.42^{\mathrm{ab}}$ & $8.66 \pm 1.47^{b}$ & 0 & $\begin{array}{c}21 \\
(77.8)\end{array}$ & $\begin{array}{c}6 \\
(22.2)\end{array}$ & 0 & $\begin{array}{c}12 \\
(66.7)\end{array}$ & $\begin{array}{c}6 \\
(33.3)\end{array}$ \\
\hline P value & \multicolumn{2}{|c|}{0.023} & \multicolumn{6}{|c|}{0.223} \\
\hline
\end{tabular}

Similar superscripted letters denote significant difference between groups within same row. 


\begin{tabular}{llcr}
\hline Group I (N=70) & $17.56 \pm 1.69^{\mathrm{ab}}$ & $15.19 \pm 0.75^{\mathrm{bc}}$ & $<0.001$ \\
\hline Group II (N=18) & $18.22 \pm 1.89^{\mathrm{ab}}$ & $16.0 \pm 1.029^{\mathrm{bc}}$ & $<0.001$ \\
\hline Control $(\mathbf{N}=\mathbf{2 7})$ & $17.41 \pm 1.76^{\mathrm{ab}}$ & $18.1 \pm 2.212^{\mathrm{bc}}$ & 0.03
\end{tabular}

Table 4: MELD score at baseline and 12 weeks post-treatment among the studied groups.

Similar superscripted letters denote significant difference between groups within same row

Table 5: clinical outcomes and complications 12 week post-treatment among the studied groups.

\begin{tabular}{|c|c|c|c|c|}
\hline Variable & $\begin{array}{c}\text { Group I } \\
(\mathrm{N}=56)\end{array}$ & $\begin{array}{c}\text { Group II } \\
(\mathbf{N}=13)\end{array}$ & $\begin{array}{l}\text { Control group } \\
(\mathbf{N}=\mathbf{1 8})\end{array}$ & P value \\
\hline Ascites & $16(28.6 \%)$ & $1(7.7 \%)$ & $10(55.6 \%)$ & $\begin{array}{l}\mathrm{p} 1=0.001 \\
\mathrm{p} 2=0.001 \\
\mathrm{p} 3=0.001\end{array}$ \\
\hline Variceal bleeding & $0(0 \%)$ & $0(0 \%)$ & $6(33.3 \%)$ & $\begin{array}{c}\mathrm{p} 1=1.0 \\
\mathrm{p} 2=0.001 \\
\mathrm{p} 3=0.006\end{array}$ \\
\hline SBP & $2(3.5 \%)$ & $0(0.0 \%)$ & $3(16.7 \%)$ & $\begin{array}{c}\mathrm{p} 1=1.0 \\
\mathrm{p} 2=1.0 \\
\mathrm{p} 3=0.26\end{array}$ \\
\hline Pleural effusion & $2(3.6 \%)$ & $0(0.0 \%)$ & $2(11.1 \%)$ & $\begin{array}{c}\mathrm{p} 1=1.0 \\
\mathrm{p} 2=1.0 \\
\mathrm{p} 3=0.51\end{array}$ \\
\hline Hepatic Encephalopathy & $2(3.6 \%)^{\mathrm{a}}$ & $0(0 \%)^{b}$ & $13(72.2 \%)$ & $\begin{array}{c}\mathrm{p} 1=1.0 \\
\mathrm{p} 2<0.001 \\
\mathrm{p} 3<0.001\end{array}$ \\
\hline Hepatorenal Syndrome & $1(1.8 \%)$ & $0(0.0 \%)$ & $2(11.1 \%)$ & $\begin{array}{c}\mathrm{p} 1=1.0 \\
\mathrm{p} 2=0.18 \\
\mathrm{p} 3=0.51\end{array}$ \\
\hline $\begin{array}{l}\text { Hepatocellular } \\
\text { carcinoma }\end{array}$ & $4(7.1 \%)$ & $0(0.0 \%)$ & $3(16.7 \%)$ & $\begin{array}{l}\mathrm{p} 1=0.58 \\
\mathrm{p} 2=0.39 \\
\mathrm{p} 3=0.26\end{array}$ \\
\hline
\end{tabular}

Used tests: Monte Carlo test \& Chi-Square test, p1 = difference between group I and group II, p2= difference between group I and control group, $3=$ difference between group II and control group.

Several open label clinical trials of DAA in decompensated HCV patients have recent confirmed that, SVR rates are associated with improvements in the ChildPugh-Turcotte (CPT) and/or model for end-stage liver disease (MELD) scores in a significant proportion of patients after relatively short follow up 20,21. Similar results have been reported by many previous studies about improvement in CTP score 12 weeks after the cessation of DAAs therapy in advanced $\mathrm{HCV}$-associated liver cirrhotic patients 22, 23. Interestingly, A study from the European Liver and Intestine Association celebrated that, 20.4\% with decompensated cirrhosis were delisted from the liver transplant list due to clinical improvement after a period of 60 weeks post-SVR; and $33 \%$ were inactivated with a median MELD improvement of 3.4 points and CTP improvement of 2 points. Delisted patients had either a complete regression or an improvement in signs of hepatic decompensation $^{24,25}$. 


\section{Original Article}

Regarding complications and adverse events occurred in our study we observed that, there is statistically significant decrease in variceal bleeding, ascites and hepatic encephalopathy in both group I and group II compared to control group, however no statistically significant difference recorded between the three studied groups regarding other complications such as hepatocellular carcinoma, hepatorenal syndrome, spontaneous bacterial peritonitis and pleural effusion. In accordance with these results, Romano et al, reported that variceal bleeding was absent in $32 \%$ of patients 3 months post-SVR and in $27 \%$ of patients 12 months post-SVR and the study concluded that decompensated HCV cirrhosis patients who achieved SVR with DAA treatment had significant reductions in manifestations of hepatic decompensation sustainable up to 1 year post-SVR ${ }^{26}$.

Also, Hanafy et al, showed a statistically significant increase in hepatic encephalopathy in control group compared to treated group $(p=0.001)$. Death in control group was recorded in $18 / 80$ patients $(22.5 \%)$ due to spontaneous bacterial peritonitis and hepatorenal syndrome $(n=4)$, hepatic encephalopathy $(n=6)$, gastrointestinal bleeding $(\mathrm{n}=8){ }^{17}$. Yet, several studies reported that viral clearance does not eliminate the risk of variceal progression, liver decompensation and death in patients with pre-established portal hypertension ${ }^{27}$

\section{Conclusion}

Treatment of decompensated HCV cirrhotic patients with CTP score $\geq 7$ (class B or C) by DAAs had steered to SVR in about $91 \%$ of patients with improvement in CTP and MELD scores and a significant reduction in variceal bleeding and hepatic encephalopathy with better control of ascites and improvement of synthetic liver functions. Addition of RBV and shortening the treatment period to 12 weeks proved to have the same outcome with no significant difference regarding SVR achievement and complications during treatment and follow up.

\section{References}

1. Gomaa A, Allam N, Elsharkway A, et al (2017). Hepatitis C infection in Egypt: prevalence, impact and management strategies. Hepatic medicine: evidence and research 17 (1): 9-17.

2. Lingala S and Ghany MG (2015). Natural history of hepatitis C. Gastroenterology Clinics, 44(4), 717-734.

3. Younossi, Z. M., Stepanova, M., Afdhal, N., et al. (2015). Improvement of health-related quality of life and work productivity in chronic hepatitis $\mathrm{C}$ patients with early and advanced fibrosis treated with ledipasvir and sofosbuvir. Journal of hepatology, 63(2), 337-345.

4. Mousa, N., Abdel-Aziz, M., Farag, R., et al. (2018). Recent trends in chronic hepatitis $\mathrm{C}$ virus treatment. Med J Viral Hepatitis.2 (2), 1-6.

\section{Medical Journal of Viral Hepatitis (MJVH)}

5. Dina, E., Nasser, M., Sarah, E., et al. (2020). Pretreatment serum alpha fetoprotein and its relation to sustained virologic response in patients with chronic HCV infection treated with direct-acting antiviral therapy. Medical Journal of Viral Hepatitis, 4(2), 69-73.

6. Shiha, G., El-Basiouny, M., Soliman, R., et al. (2016). Sofosbuvir plus ribavirin for treatment-naive chronic $\mathrm{HCV}$ genotype 4 patients: real-life experience. Medical Journal of Viral Hepatitis (MJVH), 2-8.

7. Saxena, V., Nyberg, L., Pauly, M., et al. (2015). Safety and efficacy of simeprevir/sofosbuvir in hepatitis $\mathrm{C}$-infected patients with compensated and decompensated cirrhosis. Hepatology, 62(3), 715-725.

8. Van der Meer, A. J., and Berenguer, M. (2016). Reversion of disease manifestations after $\mathrm{HCV}$ eradication. Journal of hepatology, 65(1), S95-S108.

9. Feld, J. J., Ramji, A., Shafran, S. D., et al. (2017). Ledipasvir-sofosbuvir plus ribavirin in treatmentnaive patients with hepatitis $\mathrm{C}$ virus genotype 3 infection: an open-label study. Clinical Infectious Diseases, 65(1), 13-19.

10. Feld, J. J., Jacobson, I. M., Hézode, C., et al. (2015). Sofosbuvir and velpatasvir for HCV genotype 1, 2, 4, 5 , and 6 infection. New England Journal of Medicine, 373(27), 2599-2607.

11. Maan, R., van Tilborg, M., Deterding, K., et al. (2016). Safety and effectiveness of direct-acting antiviral agents for treatment of patients with chronic hepatitis C virus infection and cirrhosis. Clinical Gastroenterology and Hepatology, 14(12), 1821-1830.

12. Hepatitis C guidance 2018 update: AASLD-IDSA recommendations for testing, managing, and treating hepatitis C virus infection. Clinical Infectious Diseases, 2018, 67.10: 1477-1492.

13. European Association for The Study of The Liver. (2018). EASL recommendations on treatment of hepatitis C 2018. Journal of hepatology, 69(2), 461511.

14. Krassenburg, L. A., Maan, R., Ramji, A., Manns, M. P., et al. (2021). Clinical outcomes following DAA therapy in patients with HCV-related cirrhosis depend on disease severity. Journal of Hepatology, 74(5), 1053-1063.

15. Omar, H., El Akel, W., Elbaz, T., et al. (2018). Generic daclatasvir plus sofosbuvir, with or without ribavirin, in treatment of chronic hepatitis C: realworld results from 18378 patients in Egypt. Alimentary pharmacology \& therapeutics, 47(3), 421431.

16. Wahsh, E. A., Hussein, A. K., Gomaa, A. A., et al. (2018). Real Life Egyptian Experience of Daclatasvir plus Sofosbuvir with Ribavirin in Naive Difficult to Treat HCV Patients. Infectious Disorders-Drug 
Targets (Formerly Current Drug Targets-Infectious Disorders), 20(1), 43-48.

17. Hanafy, A. S., Bassiony, M. A., and Basha, M. A. A. (2019). Management of HCV-related decompensated cirrhosis with direct-acting antiviral agents: who should be treated?. Hepatology international, 13(2), 165-172.

18. Welzel, T. M., Petersen, J., Herzer, K., et al. (2016). Daclatasvir plus sofosbuvir, with or without ribavirin, achieved high sustained virological response rates in patients with $\mathrm{HCV}$ infection and advanced liver disease in a real-world cohort. Gut, 65(11), 18611870.

19. Verna, E. C., Morelli, G., Terrault, N. A., et al. (2020). DAA therapy and long-term hepatic function in advanced/decompensated cirrhosis: Real-world experience from HCV-TARGET cohort. Journal of hepatology, 73(3), 540-548.

20. Welzel, T. M., Herzer, K., Ferenci, P., et al. (2015). P0772: Daclatasvir plus sofosbuvir with or without ribavirin for the treatment of $\mathrm{HCV}$ in patients with severe liver disease: Interim results of a multicenter compassionate use program. Journal of Hepatology, (62), S619-S620.

21. Nelson, D. R., Cooper, J. N., Lalezari, J. P., et al. (2015). All-oral 12-week treatment with daclatasvir plus sofosbuvir in patients with hepatitis $\mathrm{C}$ virus genotype 3 infection: ALLY-3 phase III study. Hepatology, 61(4), 1127-1135.

22. Foster, G. R., Irving, W. L., Cheung, M. C., et al. (2016). Impact of direct acting antiviral therapy in patients with chronic hepatitis $\mathrm{C}$ and decompensated cirrhosis. Journal of hepatology, 64(6), 1224-1231.

23. Poordad, F., Schiff, E. R., Vierling, J. M., et al. (2016). Daclatasvir with sofosbuvir and ribavirin for hepatitis $\mathrm{C}$ virus infection with advanced cirrhosis or post-liver transplantation recurrence. Hepatology, 63(5), 1493-1505.

24. Belli, L. S., Berenguer, M., Cortesi, P. A., et al. (2016). Delisting of liver transplant candidates with chronic hepatitis $\mathrm{C}$ after viral eradication: A European study. Journal of hepatology, 65(3), 524-531.

25. Belli, L. S., Duvoux, C., Berenguer, M., et al. (2017). ELITA consensus statements on the use of DAAs in liver transplant candidates and recipients. Journal of hepatology, 67(3), 585-602.

26. Romano, J., Sims, O. T., Richman, J., et al. (2018). Resolution of ascites and hepatic encephalopathy and absence of variceal bleeding in decompensated hepatitis $\mathrm{C}$ virus cirrhosis patients. JGH Open, 2(6), 317-321.

27. Libânio, D., and Marinho, R. T. (2017). Impact of hepatitis $\mathrm{C}$ oral therapy in portal hypertension. World journal of gastroenterology, 23(26), 4669. 